\title{
Medical and sociodemographic factors predict persistent smoking after coronary events
}

Elise Sverre ${ }^{1,2^{*}}$ (D, Jan Erik Otterstad ${ }^{3}$, Erik Gjertsen ${ }^{1}$, Lars Gullestad ${ }^{4}$, Einar Husebye ${ }^{1}$, Toril Dammen ${ }^{2}$, Torbjørn Moum ${ }^{2}$ and John Munkhaugen ${ }^{1}$

\begin{abstract}
Background: Understanding the determinants of persistent smoking after a coronary event constitutes the basis of modelling interventions of smoking cessation in secondary prevention programs. We aim to identify the potentially modifiable medical, sociodemographic and psychosocial factors, comprising the study factors, associated with unfavourable risk factor control after CHD events.

Methods: A cross-sectional explorative study used logistic regression analysis to investigate the association between study factors and smoking status in 1083 patients hospitalized with myocardial infarction and/or coronary revascularization. Hospital record data, a self-report questionnaire, clinical examination and blood samples were applied.

Results: At the index hospitalization, 390 patients were smoking and at follow-up after 2-36 months 167 (43\%) of these had quit, while 230 reported persistent smoking. In adjusted analyses, unemployed or disability benefits (Odds ratio (OR) 4.1), low education (OR 3.5), longer smoking duration (OR 2.3) and not having ST-elevation myocardial infarction (STEMI) as index event (OR 2.3) were significantly associated with persistent smoking. Psychosocial factors at follow-up were not associated with persistent smoking. Smokers reported high motivation for cessation, with 68\% wanting help to quit. Only 42\% had been offered nicotine replacement therapy or other cessation aids. Smokers rated use of tobacco as the most important cause of their coronary disease (6.8 on a 1-10 Likert scale).
\end{abstract}

Conclusions: Low socioeconomic status, prior duration of smoking, and not having STEMI as index event were associated with persisting smoking. Persistent smokers in this study seem to have an acceptable risk perception and were motivated to cease smoking, but needed assistance through cessation programs including prescription of pharmacological aids.

Trial registration: Registered at ClinicalTrials.gov: NCT02309255, registered retrospectively.

Keywords: Smoking, Smoking cessation, Coronary heart disease (CHD), Secondary prevention, Sociodemographic factors, Medical risk factors, Psychosocial risk factors

\footnotetext{
*Correspondence: elisbj@vestreviken.no

'Department of Medicine, Drammen Hospital, PB 800, 3004 Drammen,

Norway

2Department of Behavioural Sciences in Medicine, University of Oslo, Oslo,

Norway

Full list of author information is available at the end of the article
} International License (http://creativecommons.org/licenses/by/4.0/), which permits unrestricted use, distribution, and reproduction in any medium, provided you give appropriate credit to the original author(s) and the source, provide a link to the Creative Commons license, and indicate if changes were made. The Creative Commons Public Domain Dedication waiver (http://creativecommons.org/publicdomain/zero/1.0/) applies to the data made available in this article, unless otherwise stated. 


\section{Background}

The causal role of cigarette smoking in the development and progression of coronary heart disease (CHD) is overwhelmingly documented $[1,2]$. Smoking is the leading avoidable cause of death in the developed world [3] and increases the risk of coronary events [4] and total mortality by up to $50 \%[1,4]$. Smoking thus remains the single most important cardiovascular risk factor to modify in order to improve prognosis in CHD patients [2-4].

Different smoking cessation programs and pharmacological treatment [5-7] increase the likelihood of cessation in clinical studies. Still, clinical practice across Europe suggests that about half of the daily smokers surviving a coronary event continue smoking [8]. While the prevalence of daily smoking in the general European population decreased substantially over the past decade [9], only a modest reduction (20\% to $16 \%$ ) was seen in CHD patients over the past 20 years in the EuroAspire studies $[8,10]$. In the US, the reduction in the number of daily smokers from 1980 to 2000 was $12 \%$ in the general population compared to $5 \%$ in $\mathrm{CHD}$ patients [11]. It is concerning that the prevalence of daily smoking actually has increased among the youngest CHD patients [10].

A complex array of patient and healthcare factors influence smoking behaviour in coronary patients [2, 3, 12-17]. Identification of potentially modifiable medical and psychosocial factors associated with persistent smoking after coronary events could be important for the development of individually tailored interventions of smoking cessation with sustained effect $[2,5,7,18]$.

The NORwegian-CORonary (NOR-COR) Prevention Study identifies sociodemographic, medical, and psychosocial factors, comprising the study factors, associated with unfavourable risk factor control after CHD events (phase I). Moreover, the project aims to target the study factors of importance for risk factor control in tailored interventions (phase II) [18]. The present exploratory analysis aims to identify the study factors associated with persistent smoking in a cross-sectional survey.

\section{Methods}

\section{Design and population}

The design, methods, and baseline characteristics of the NOR-COR Study have been described elsewhere [18]. A cross-sectional study was conducted at two general Norwegian hospitals (Drammen and Vestfold) with a total catchment area of 380,000 inhabitants, corresponding to $7.4 \%$ of the Norwegian population. In total, 1789 consecutive patients aged 18-80 years with a first or recurrent coronary event/treatment (i.e. acute myocardial infarction, coronary artery by-pass graft operation, and/or percutaneous coronary intervention) were identified from hospital discharge lists over the three years (2011-14) prior to study inclusion. The index event was defined as the last coronary event prior to inclusion. Of the identified patients, 423 were excluded due to cognitive impairment $(n=28)$, psychosis $(n=18)$, drug abuse $(n=10)$, short life expectancy $(n=136)$, death $(n=160)$, not being able to understand Norwegian language $(n=44)$, and other $(n=26)$. Of the remaining 1366 eligible patients, $1127(83 \%)$ consented to participate in attending a clinical visit and completing a comprehensive questionnaire [18] at 2-36 months follow-up after the index event. Smoking status at follow-up was missing in 44 patients, leaving 1083 in the final analyses. As smoking status at the index event was missing in seven patients who reported daily smoking at follow-up, there is thus a minor discrepancy between the proportion of smokers reported at index event and at follow-up.

All participants gave informed consent before study participation. The NOR-COR study was approved by the Regional Committee of Ethics (REK Sør-Øst) 12. February, $2014(2013 / 1885)$.

\section{Outcome assessment}

The primary outcome variable was smoking status at follow-up compared to smoking status at the index event, categorized as persistent smoker vs. quitter. Smoking status at index event was recovered from hospital medical records. Patients who smoked at the time of the index event were categorized as current smokers. Smoking at follow-up was recorded from the self-report questionnaire. All patients who reported daily smoking [cigarettes $(n=225)$, pipes $(n=0)$ or cigars $(n=5)]$ were categorized as persistent smokers.

\section{Covariates (study factors)}

Study data registered at the time of the index event

Demographic variables, risk factors, somatic comorbidity summarized according to the Charlson comorbidity index [19] and information about the index coronary event and treatment were registered from hospital medical records [18].

\section{Study factors registered at follow-up 2-36 months after the index event}

Sociodemographic factors included marital status, education, and employment status. Medical factors included coronary risk factors and cardiovascular medication. Psychosocial factors included anxiety and depression (Hospitality Anxiety and Depression Scale) [20], Type D personality [21], worry (Penn State Worry Questionnaire) [22], insomnia (Bergen Insomnia Scale) [23], illness perception (Brief illness perception questionnaire) [24] and perceived risk [25]. Moreover, information about smoking behaviour, motivation and treatment needs were obtained by the self-report questionnaire [18]. Participation in cardiac rehabilitation programs was based on hospital 
medical records, including lists from the cardiac rehabilitation departments.

\section{Statistics}

Using SPSS version 21, data were analysed in a crosssectional design with the study factors as the main exposure variables and smoking status (persistent smokers vs. quitters) at follow-up as the main outcome variable. The distribution of study factors according to smoking status (never smoker, former smoker, current smoker) at the index event and at follow-up (persistent smokers, quitters) were reported as frequencies and percentages. A forward, stepwise binary logistic regression analysis was used to calculate crude and multi-adjusted odds ratio (OR) and 95\% confidence intervals (CI) for study outcomes with interaction terms between independent variables as indicated. The level of significance was set to $p<0.05$. Covariates with $p$-values between 0.05 and 0.1 in crude analyses were also selected as candidates for the multivariate analyses since more traditional levels (i.e. 0.05) can fail to identify variables that might turn out to be significant when actually included in the adjusted models.

\section{Results}

Characteristics of the study population at the time of the index event are presented in Table 1. Mean age was 62 (SD 10) years and $21 \%$ were women. A total of 390 (36\%) patients were smoking at the time of the index event. Compared to former and never smokers, the group of current smokers consisted of more females than males, and were characterized as a group by their younger age, lower education levels, more often having ST-elevation myocardial infarction (STEMI) as index event as well as having fewer previous coronary events.

Sociodemographic, medical, and psychosocial factors in persistent smokers and quitters at follow-up 2-36 (mean 16) months after the index event are shown in

Table 1 Patient characteristics according to smoking status at the index coronary event

\begin{tabular}{|c|c|c|c|}
\hline Study factors & Never smoker $(n=250)$ & Former smoker $(n=436)$ & Current smoker $(n=390)$ \\
\hline \multicolumn{4}{|l|}{ Sociodemographic factors } \\
\hline Age at index event, mean (SD) & $63.3(10.3)$ & $63.2(8.7)$ & $58.5(9.5)$ \\
\hline Number of months since the index event, mean (SD) & $16.5(10.4)$ & $16.5(10.2)$ & $18.2(10.9)$ \\
\hline Female sex, n (\%) & $51(20.4)$ & $79(18.1)$ & $97(24.9)$ \\
\hline Ethnic minority background, $\mathrm{n}(\%)$ & $12(4.8)$ & $8(1.8)$ & $11(2.8)$ \\
\hline Low education, $\mathrm{n}(\%)$ & $156(62.4)$ & $291(66.7)$ & $296(75.9)$ \\
\hline \multicolumn{4}{|l|}{ Medical factors } \\
\hline \multicolumn{4}{|l|}{ Coronary index event and treatment: } \\
\hline ST-elevation infarction, n (\%) & $54(21.6)$ & $102(23.4)$ & $167(42.8)$ \\
\hline Non-ST-elevation infarction, n (\%) & $137(54.8)$ & $218(50.0)$ & $182(46.7)$ \\
\hline Stable or unstable angina, $\mathrm{n}(\%)$ & 59 (23.6) & $116(26.6)$ & $44(11.3)$ \\
\hline More than 1 coronary event, $\mathrm{n}(\%)$ & $71(28.4)$ & $151(34.6)$ & $97(24.9)$ \\
\hline \multicolumn{4}{|l|}{ Comorbidity: } \\
\hline Charlson co-morbidity sum score, mean (SD) & $4.0(1.3)$ & $4.3(1.5)$ & $3.9(1.4)$ \\
\hline Heart failure, n (\%) & $21(8.4)$ & $65(14.9)$ & $54(13.8)$ \\
\hline Stroke or transient ischemic attack, n (\%) & $14(5.6)$ & $39(8.9)$ & $24(6.2)$ \\
\hline Peripheral artery disease, $\mathrm{n}(\%)$ & $12(4.8)$ & $39(8.9)$ & $42(10.8)$ \\
\hline Chronic obstructive pulmonary disease, $\mathrm{n}(\%)$ & $2(0.8)$ & $45(10.3)$ & $47(12.1)$ \\
\hline Hypertension, n (\%) & $129(51.6)$ & $231(53.0)$ & $249(63.8)$ \\
\hline Diabetes, n (\%) & $35(14.0)$ & $92(21.1)$ & $49(12.6)$ \\
\hline \multicolumn{4}{|l|}{ Treatment at hospital discharge } \\
\hline Aspirin, n (\%) & $247(98.8)$ & $425(97.5)$ & $387(99.2)$ \\
\hline Additional antiplatelet therapy, n (\%) & $212(84.8)$ & $373(85.6)$ & $360(92.3)$ \\
\hline Statins, n (\%) & $239(95.6)$ & $414(95.0)$ & $379(97.2)$ \\
\hline $\mathrm{ACE}^{\mathrm{a}}$ or $\mathrm{ARBS} \mathrm{s}^{\mathrm{b}}, \mathrm{n}(\%)$ & $141(56.4)$ & $249(57.1)$ & $207(53.1)$ \\
\hline Beta-blockers, n (\%) & $212(84.8)$ & $373(85.6)$ & $329(84.4)$ \\
\hline
\end{tabular}

${ }^{\mathrm{a}} \mathrm{ACEl}$, angiotensin converting enzyme inhibitor

${ }^{\mathrm{b}} \mathrm{ARB}$ angiotensin receptor blocker 
Table 2. At follow-up, 167 (43\%) of the registered smokers at the index event had quit smoking, while 230 patients reported persistent smoking. Almost all persistent smokers had been smoking for 20 years or more, and $60 \%$ had been smoking for more than 40 years. Seventy-three percent of the persistent smokers reported having reduced their cigarette use since the index event. In bivariate analyses, low education, living alone, unemployed or disability benefit, longer smoking duration, more than one coronary event prior to the index event, non-participation in cardiac rehabilitation, not having STEMI as index event, low physical activity, and no prescription of statins were significantly more prevalent in persistent smokers than in quitters. No significant differences in psychosocial factors were found between persistent smokers and quitters. These findings were consistent in sub-group analyses by age and gender.

The persistent smokers reported a high motivation (average 7.8 on a 1-10 Likert scale) for smoking cessation and only $14 \%$ reported low $(\leq 3)$ motivation. Sixty eight percent wanted help to quit smoking. However, only $42 \%$ reported having been offered nicotine replacement therapy or any other form of cessation aid. In total, $35 \%$ of the persistent smokers and $27 \%$ of the quitters $(p=0.14)$

Table 2 Sociodemographic, medical, and psychosocial factors in smokers and quitters at follow-up a after the coronary event

\begin{tabular}{|c|c|c|c|}
\hline Study factors & Quitted after the index event $(n=167)$ & Persistent smokers $(n=230)$ & $p$-value \\
\hline \multicolumn{4}{|l|}{ Sociodemographic factors } \\
\hline Age at index event, mean (SD) & $57.7(9.4)$ & $59.3(9.3)$ & $p=0.05$ \\
\hline Number of months since the index event, mean (SD) & $16.8(10.9)$ & $18.9(10.8)$ & $p=0.05$ \\
\hline Female sex, n (\%) & $38(22.8)$ & $56(24.3)$ & $p=0.71$ \\
\hline Ethnic minority background, n (\%) & $4(2.4)$ & $10(4.3)$ & $p=0.30$ \\
\hline Living alone, n (\%) & $28(16.8)$ & $57(24.8)$ & $p<0.05$ \\
\hline Low education, $\mathrm{n}(\%)$ & $116(69.5)$ & $189(82.2)$ & $p<0.001$ \\
\hline Unemployed or on disability benefits, n (\%) & $33(19.8)$ & $85(37.0)$ & $p<0.001$ \\
\hline \multicolumn{4}{|l|}{ Medical factors } \\
\hline \multicolumn{4}{|l|}{ Duration of smoking, years, n (\%) } \\
\hline$<20$ & $11(6.6)$ & $8(3.5)$ & $p<0.001$ \\
\hline 20-39 & $99(59.3)$ & $64(27.8)$ & \\
\hline$>40$ & $53(31.7)$ & $137(59.6)$ & \\
\hline $\begin{array}{l}\text { ST-elevation infarction/non ST-elevation infarction and } \\
\text { angina, n (\%) }\end{array}$ & $78(46.7) / 89(53.3)$ & $84(36.5) / 146(63.5)$ & $p<0.05$ \\
\hline More than 1 coronary event, $\mathrm{n}(\%)$ & $30(18.0)$ & $77(33.5)$ & $p<0.001$ \\
\hline Participation in cardiac rehabilitation, n (\%) & $95(56.9)$ & $103(44.8)$ & $p<0.05$ \\
\hline Charlson co-morbidity sum score, mean (SD) & $3.8(1.3)$ & $4.0(1.4)$ & $p=0.14$ \\
\hline Use of antiplatelets at follow-up, n (\%) & $164(98.2)$ & $221(96.1)$ & $p=0.22$ \\
\hline Use of statins at follow-up, n (\%) & $160(95.8)$ & $207(90.0)$ & $p<0.05$ \\
\hline Low physical activity ${ }^{\mathrm{b}}, \mathrm{n}(\%)$ & $93(55.7)$ & $186(80.9)$ & $p<0.001$ \\
\hline Body Mass Index >30 kg/m², n (\%) & $61(36.5)$ & $58(25.2)$ & $p<0.05$ \\
\hline Low density lipoprotein cholesterol >1.8 mmol/l, n (\%) & $88(52.7)$ & $124(53.9)$ & $p=0.66$ \\
\hline Blood pressure > 140/90 (140/80 diabetes) mmHg, $\mathrm{n}(\%)$ & $60(35.9)$ & $74(32.2)$ & $p=0.74$ \\
\hline Diabetes, n (\%) & $16(9.6)$ & $36(15.7)$ & $p=0.08$ \\
\hline \multicolumn{4}{|l|}{ Psychosocial factors } \\
\hline Hospital Anxiety and Depression Score - depression $\geq 11, \mathrm{n}(\%)$ & $12(7.2)$ & $13(5.7)$ & $p=0.61$ \\
\hline Hospital Anxiety and Depression Score - anxiety $\geq 11, \mathrm{n}(\%)$ & $22(13.2)$ & $27(11.7)$ & $p=0.81$ \\
\hline Type D personality disorder, n (\%) & $41(24.6)$ & $56(24.3)$ & $p=0.89$ \\
\hline Worry score (PSWQ'), mean (SD) & $40.1(13.9)$ & $40.3(13.9)$ & $p=0.87$ \\
\hline Insomnia $^{d}, \mathrm{n}(\%)$ & $80(47.9)$ & $114(49.6)$ & $p=0.65$ \\
\hline
\end{tabular}

${ }^{2}$-36 months after the index coronary event

b Physical activity less than 30 min of moderate activity 2-3 times weekly

'Worry was assessed by the Penn State Worry Questionnaire (PSWQ), a 16 item measure of pathological worry

${ }^{\mathrm{d}}$ Measured by Bergen insomnia Scale 
reported having no current follow-up for their CHD in primary or specialist healthcare. Smoking was rated as the most important cause of CHD by both persistent smokers and quitters, but quitters rated the importance of smoking as risk factor higher (7.5 vs. 6.8 on a 1-10 Likert scale, $p<0.05)$. Persistent smokers felt they had a higher likelihood of having a new heart attack within the next 12 months than quitters ( 3.3 vs. 2.5 on a $1-10$ Likert scale, $p<0.01)$. They also felt they could do less to help reduce that risk (6.4 vs. 7.0 on a $1-10$ Likert scale, $\mathrm{p}<0.05)$. Compared to quitters, persistent smokers thought they would have to restrict their daily activities more in the long-term (3.0 vs. 4.2 on a $1-10$ Likert scale, $p<0.001)$. Persistent smokers scored significantly lower on treatment control compared to quitters ( 7.8 vs. 6.6 on a $1-10$ Likert scale, $p<0.001$ ), while no other differences in illness perception were found. A considerable subgroup of both persistent smokers $(21 \%)$ and quitters (13\%) perceived "no need to change lifestyle".

The odds ratios for persistent smoking compared to quitting smoking after the index event by study factors are shown in Table 3. In crude analyses, unemployment or disability benefits were the strongest predictors of persistent smoking, followed by longer duration of smoking, low education, $>1$ coronary event, living alone, no participation in cardiac rehabilitation and not having STEMI as index event. In multi-adjusted analyses the study factors significantly associated with persistent smoking were: unemployment or disability benefits, low education, longer duration of smoking, and not having STEMI as index event.

\section{Discussion}

Almost $60 \%$ of patients in routine clinical practice persisted smoking 2-36 months after a coronary event. In particular, low socioeconomic status, longer duration of smoking and not having STEMI as index event were associated with persistent smoking in multi-adjusted analyses, while psychosocial factors and participation in cardiac rehabilitation were not. Almost all persistent smokers had been smoking for a long time, with $60 \%$ having been smokers for more than 40 years. Most persistent smokers seemed to be aware of the risk associated with smoking and reported a high motivation for cessation. More than $70 \%$ of persistent smokers had reduced the number of cigarettes smoked after the index event. However, only $42 \%$ reported having been offered any smoking cessation aids, and $35 \%$ had no current follow-up in primary or specialist healthcare for their CHD.

Low education, unemployment and the claiming of disability benefit $\mathrm{s}$ were the factors most strongly associated with persistent smoking, concurring to the well-established inverse association between smoking and socioeconomic status [2, 3, 26]. Even though socioeconomic position is not easily modified, our findings suggest that these patients should be systematically identified during hospitalisation for coronary events and offered smoking cessation programs.

In the present study, STEMI as the coronary index event was significantly associated with quitting smoking. A qualitative study finding that the urgency of managing STEMI bolsters the impression of suffering a life-threatening event could be relevant in this context since such a perception may increase the patient's motivation and willingness to change lifestyle [27]. In contrast, the initial uncertainty of the diagnosis in non ST-elevation myocardial infarction (NSTEMI) and unstable angina pectoris may lead to reduced appreciation of the seriousness of the condition [27]. The majority of persistent smokers in the present study, however, appear to be aware of the risk associated with smoking, with smoking rated as the most important cause of CHD.

Most persistent smokers reported a high motivation for smoking cessation and 73\% reported having reduced their smoking since the coronary event, while almost $70 \%$ reported that they wanted immediate assistance with cessation. Even though we have not measured the different stages of change [28], this suggests that these patients have passed the pre-contemplation stage (i.e. no intention to quit). By comparison, $50 \%$ of CHD patients smoking at follow-up had passed the pre-contemplation stage in the EuroAspire III study. As recommended in clinical guidelines [2], motivation and readiness for smoking cessation should be assessed in all patients admitted to hospital for coronary events. A long smoking history, the reported reduction in consumption of cigarettes and the high level of motivation for cessation without success suggest substantial nicotine dependency. Nicotine dependency is a well-known barrier to smoking cessation $[12,14]$, and the longer the duration of smoking, the less likely is a change in smoking behaviour [28]. It is of concern, therefore, that only $42 \%$ of the persistent smokers in the present study had been offered cessation aid, which is in accordance with other studies of CHD patients $[29,30]$. Smoking receives less attention from cardiologists than other risk factors [12], possibly because physicians believe themselves to possess limited intervention skills in behavioural counselling [16]. It may also reflect a reluctance among health professionals to believe that their patients have the ability to quit smoking. This may partly explain why smoking cessation therapy is not offered as indicated [16].

Surprisingly, none of the measured psychosocial factors (anxiety, depression, worry, insomnia, type D personality) differed between quitters and persistent smokers on average 1.7 years after the index coronary event. Our findings are contrary to studies reporting that individuals with depression are more likely to smoke and less likely to quit 
Table 3 Odds ratios for persistent smoking after the coronary index event calculated with logistic regression analysis

\begin{tabular}{|c|c|c|c|c|}
\hline \multirow[t]{2}{*}{ Study factors } & Model $1(\mathrm{OR}, 95 \% \mathrm{Cl})$ & $p$-value & Model $2(\mathrm{OR}, 95 \% \mathrm{Cl})$ & $p$-value \\
\hline & \multicolumn{2}{|l|}{ Crude $^{a}$} & \multicolumn{2}{|l|}{ Multi-adjusted $^{b}$} \\
\hline \multicolumn{5}{|l|}{ Sociodemographic factors } \\
\hline Mean age at index event (OR per year) & $1.02(1.00-1.04)$ & $p=0.05$ & $0.97(0.90-1.03)$ & $p=0.27$ \\
\hline Time since the index event (OR per year) & $1.02(1.00-1.04)$ & $p=0.05$ & $1.01(0.98-1.05)$ & $p=0.41$ \\
\hline Female gender & $1.09(0.68-1.75)$ & $p=0.71$ & $2.17(0.85-5.52)$ & $p=0.10$ \\
\hline Living alone & $1.69(1.01-2.82)$ & $p<0.05$ & $1.23(0.48-3.11)$ & $p=0.67$ \\
\hline Low education & $2.20(1.36-3.57)$ & $p=0.001$ & $3.35(1.43-7.81)$ & $p<0.01$ \\
\hline Unemployed or on disability benefits & $3.01(1.81-5.02)$ & $p<0.001$ & $4.12(1.80-9.41)$ & $p=0.001$ \\
\hline \multicolumn{5}{|l|}{ Medical factors } \\
\hline Not having ST-elevation infarction as index event & $1.53(1.02-2.29)$ & $p<0.05$ & $2.30(1.08-4.40)$ & $p<0.05$ \\
\hline More than 1 coronary event & $2.30(1.42-3.72)$ & $p=0.001$ & $1.53(0.63-3.72)$ & $p=0.35$ \\
\hline Participation in cardiac rehabilitation & $0.62(0.41-0.92)$ & $p<0.05$ & $0.78(0.38-1.60)$ & $p=0.50$ \\
\hline Charlson co-morbidity sum score & $1.12(0.96-1.32$ & $p=0.14$ & & \\
\hline Duration of smoking (years) & $2.93(1.62-2.71)$ & $p<0.001$ & $2.34(1.41-3.88)$ & $p=0.001$ \\
\hline \multicolumn{5}{|l|}{ Psychosocial factors } \\
\hline Hospital Anxiety and Depression Score - total > 11 & $1.06(0.70-1.62)$ & $p=0.78$ & & \\
\hline Type D personality & $1.03(0.65-1.65)$ & $p=0.89$ & & \\
\hline Worry score (PSWQ') & $1.00(0.99-1.01)$ & $p=0.87$ & & \\
\hline Insomnia $^{d}$ & $1.10(0.73-1.65)$ & $p=0.65$ & & \\
\hline \multicolumn{5}{|l|}{ Perceived risk (1-10 Likert scale) } \\
\hline $\begin{array}{l}\text { What do you feel is the likelihood of having a new heart attack over the } \\
\text { next } 12 \text { months? }\end{array}$ & $1.15(1.05-1.25)$ & $p<0.01$ & $1.01(0.86-1.18)$ & $p=0.93$ \\
\hline $\begin{array}{l}\text { How much do you feel you can help reduce your risk of having another } \\
\text { heart attack? }\end{array}$ & $0.91(0.84-0.99)$ & $p<0.05$ & $0.88(0.76-1.02)$ & $p=0.09$ \\
\hline $\begin{array}{l}\text { How much do you think you will have to restrict your activities in the } \\
\text { long-term du to your heart condition? }\end{array}$ & $1.17(1.08-1.27)$ & $p<0.001$ & $1.00(0.87-1.17)$ & $p=0.90$ \\
\hline \multicolumn{5}{|l|}{ Brief IIIness Perception Questionnaire (1-10 Likert scale) } \\
\hline How much does your illness affect your life? (consequences) & $0.99(0.92-1.06)$ & $p=0.76$ & & \\
\hline How long do you think your illness will continue? (timeline) & $0.98(0.91-1.04)$ & $p=0.45$ & & \\
\hline $\begin{array}{l}\text { How much control do you feel you have over your illness? (personal } \\
\text { control) }\end{array}$ & $0.95(0.88-1.02)$ & $p=0.16$ & & \\
\hline How much do you think your treatment can help you? (treatment control) & $0.80(0.72-0.88)$ & $p<0.001$ & $0.88(0.75-1.02)$ & $p=0.09$ \\
\hline How much do you experience symptoms from your illness? (identity) & $0.83(0.92-1.07)$ & $p=0.83$ & & \\
\hline How concerned are you about your illness? (concern) & $0.98(0.93-1.06)$ & $p=0.74$ & & \\
\hline How well do you feel you understand your illness? (understanding) & $0.97(0.89-1.05)$ & $p=0.41$ & & \\
\hline How much does your illness affect you emotionally? (emotional response) & $0.96(0.90-1.02)$ & $p=0.19$ & & \\
\hline
\end{tabular}

Quitted smoking after the index event is the reference category

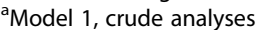

${ }^{\mathrm{b}}$ Model 2, multi-adjusted with including all variables with $p<0.1$ in crude analysis (adjusted for all variables included in the model)

'Worry was assessed by the Penn State Worry Questionnaire (PSWQ), a 16 item measure of pathological worry

${ }^{\mathrm{d}}$ Measured by Bergen insomnia Scale

smoking successfully [31, 32]. Other studies have found no association between persistent smoking and either depression or anxiety [33]. The frequency of smoking in patients with type $\mathrm{D}$ personality is higher than in patients without type D in some studies [34], while others have found no differences [35]. The level of psychosocial distress decreases with increasing time since the coronary event [36] and the timing of assessment of psychosocial factors may explain the conflicting association between smoking and psychosocial factors observed in previous studies. Variation in measurement methods used for evaluation of psychological symptoms $[32,37]$ is another possible explanation. Psychosocial factors were not measured at the index event 
and we therefore do not know if these factors predict persistent smoking at follow up.

In accordance with two randomized clinical trials $[38,39]$, we found no effect of participation in cardiac rehabilitation on smoking cessation in adjusted analyses. The most recent Cochrane review on cardiac rehabilitation programs [40] did not address the effect of cardiac rehabilitation on smoking cessation, while the 2004 review [41] found a small positive effect of cardiac rehabilitation on cessation. Better smoking cessation interventions are urgently needed in clinically implemented cardiac rehabilitation programs [2].

A Cochrane review of tobacco treatment trials found that intensive counselling, initiated during hospitalization, significantly increased quit rates at 12 months follow-up [7]. Adding nicotine replacement therapy further increased quitting compared with counselling alone [7, 17]. The small reduction in daily smoking in CHD patients across Europe over the past few decades $[8,10]$, however, substantiates the need of novel and better strategies to ensure the implementation of evidenced based cessation programs in clinical practice. Despite a long and heavy smoking history, most patients in this cohort seem to be aware of the risk associated with smoking and were motivated to quit smoking. Hospitalization for a coronary event provides an important opportunity for quitting smoking and the chance of successful smoking cessation has recently been shown to be higher with immediate [42] and abrupt [43] quitting. Effective, proactive counselling tailored to the readiness to quit smoking should therefore be the standard of care for managing all smokers during hospitalization for the index coronary event [17]. Furthermore, systematic referral to outpatient smoking cessation programs adapted to each patient's profile and needs [18] and routinely prescribing pharmacological aids may further facilitate cessation. High risk sub-groups with low socioeconomic status, a long history of smoking and those having less dramatic coronary events such as NSTEMI or angina, are at increased risk of persistent smoking and should receive particular attention and be considered for extended follow-up.

\section{Study limitations and strengths}

Smoking and other important study factors were measured by self-reporting, and are thus prone to measurement errors and recall bias. Additional confounders should be considered. Data for the date of smoking cessation, the use of cessation aids among quitters and specific questionnaires addressing nicotine dependence were not available. We do not have enough power to perform multi-adjusted analyses in sub-groups of age and gender, but no important differences in the major study factors were found in unadjusted sub-group analyses. High participation rate $(83 \%)$, the routine clinical setting and few missing data are important strengths of the study. A reproducibility study of the NOR-COR questionnaire demonstrated highly acceptable test-retest values for all key items and instruments [44].

\section{Conclusion}

Low socioeconomic status, prior duration of smoking, and not having STEMI as index event were associated with persistent smoking in coronary patients, while psychosocial factors and participation in cardiac rehabilitation were not. A majority of persistent smokers appeared to be aware of the risk associated with smoking and were motivated for smoking cessation. Given the well-documented benefit of smoking cessation, there is considerable potential for better interventions to facilitate cessation in CHD patients, including systematic referral to cessation programs including prescription of pharmacological aids.

\section{Abbreviations}

ACEl: Angiotensin converting enzyme inhibitor; ARB: Angiotensin receptor blocker; CHD: Coronary heart disease; Cl: Confidence interval; NSTEMI: Non-ST elevation infarction; OR: Odds ratio; PSWQ: Penn State Worry Questionnaire; SD: Standard deviation; STEMI: ST-elevation myocardial infarction

\section{Acknowledgments \\ The NOR-COR project originates from the Department of Medicine Drammen Hospital and the study was carried out at Drammen and Vestfold Hospitals. The concept was developed by the project in collaboration with communities at the University of Oslo. The authors thank study patients for participating and study personnel for their invaluable contribution. The authors would also like to thank Matthew McGee, Morbid Obesity Centre, Vestfold Hospital Trust, for proofreading the manuscript.}

\section{Funding}

The study was funded by grants from the Department of Medicine, Drammen Hospital (grant number 1703001 project 9,603,003) and Department for Cardiology, the hospital of Vestfold (grant number 703110 project 19,440).

\section{Availability of data and materials}

According to Norwegian legislation, the Norwegian Data Protection Authority and the Committee of Ethics, we are not allowed to share original study data publicly. However, except for anthropometric data, the other essential data by which the conclusions in the article are based will be provided upon reasonable request from the corresponding author.

\section{Authors' contributions}

$T D, L G, E G, E H$ and JM contributed to the design of the work. ES, TM and JM contributed to the analysis and all authors contributed to the interpretation of data. ES drafted the manuscript. JM, JEO, EG, EH, TD, TM, and LG critically revised the manuscript. All contributors gave final approval and agreed to be accountable for all aspects of the work, thus ensuring integrity and accuracy.

\section{Ethics approval and consent to participate}

All participants gave informed consent before study participation.The NORCOR study was approved by the Regional Committee of Ethics (REK Sør-Øst) 12. February 2014 (2013/1885).

Consent for Publication

Not applicable.

Competing interests

The authors declare that they have no competing interests. 


\section{Publisher's Note}

Springer Nature remains neutral with regard to jurisdictional claims in published maps and institutional affiliations.

\section{Author details}

'Department of Medicine, Drammen Hospital, PB 800, 3004 Drammen, Norway. ${ }^{2}$ Department of Behavioural Sciences in Medicine, University of Oslo, Oslo, Norway. ${ }^{3}$ Department of Medicine, Vestfold Hospital, Tønsberg, Norway. ${ }^{4}$ Department of Cardiology, Oslo University Hospital Rikshospitalet, The Faculty of Medicine, University of Oslo, Oslo, Norway.

Received: 31 March 2017 Accepted: 30 August 2017 Published online: 06 September 2017

\section{References}

1. Doll R, Peto R, Boreham J, Sutherland I. Mortality in relation to smoking: 50 years' observations on male British doctors. BMJ. 2004;328(7455):1519.

2. Piepoli MF, Hoes AW, Agewall S, Albus C, Brotons C, Catapano AL, Cooney MT, Corra U, Cosyns B, Deaton C, et al. 2016 European Guidelines on cardiovascular disease prevention in clinical practice: The Sixth Joint Task Force of the European Society of Cardiology and Other Societies on Cardiovascular Disease Prevention in Clinical Practice (constituted by representatives of 10 societies and by invited experts): Developed with the special contribution of the European Association for Cardiovascular Prevention \& Rehabilitation (EACPR). Eur J Prev Cardiol. 2016;23(11):Np1-np96.

3. Edwards R. The problem of tobacco smoking. BMJ. 2004;328(7433):217-9.

4. Critchley J, Capewell S. Smoking cessation for the secondary prevention of coronary heart disease. Cochrane Database Syst Rev. 2004;1:CD003041.

5. Hartmann-Boyce J, Stead LF, Cahill K, Lancaster T. Efficacy of interventions to combat tobacco addiction: Cochrane update of 2013 reviews. Addiction. 2014;109(9):1414-25

6. Cahill K, Stevens S, Perera R, Lancaster T. Pharmacological interventions for smoking cessation: an overview and network meta-analysis. Cochrane Database Syst Rev. 2013;5:CD009329.

7. Rigotti NA, Clair C, Munafo MR, Stead LF. Interventions for smoking cessation in hospitalised patients. Cochrane Database Syst Rev. 2012;5:CD001837.

8. Kotseva K, Wood D, De Bacquer D, De Backer G, Ryden L, Jennings C, Gyberg V, Amouyel P, Bruthans J, Castro Conde A, et al. EUROASPIRE IV: A European Society of Cardiology survey on the lifestyle, risk factor and therapeutic management of coronary patients from 24 European countries. Eur J Prev Cardiol. 2016;23:636-48.

9. OECD. Saa, in Health at a Glance: Europe 2012. Paris: OECD Publishing; 2012. doi.org/10.1787/9789264183896-24-en. Accessed 3 Feb 2017

10. Kotseva K, Wood D, De Backer G, De Bacquer D, Pyorala K, Keil U. Cardiovascular prevention guidelines in daily practice: a comparison of EUROASPIRE I, II, and III surveys in eight European countries. Lancet. 2009; 373(9667):929-40.

11. Young F, Capewell S, Ford ES, Critchley JA. Coronary mortality declines in the U.S. between 1980 and 2000 quantifying the contributions from primary and secondary prevention. Am J Prev Med. 2010;39(3):228-34.

12. Rigotti NA, Clair C. Managing tobacco use: the neglected cardiovascular disease risk factor. Eur Heart J. 2013;34(42):3259-67.

13. Pogosova N, Saner H, Pedersen SS, Cupples ME, McGee H, Hofer S, Doyle F, Schmid JP, von Kanel R. Psychosocial aspects in cardiac rehabilitation: From theory to practice. A position paper from the Cardiac Rehabilitation Section of the European Association of Cardiovascular Prevention and Rehabilitation of the European Society of Cardiology. Eur J Prev Cardiol. 2015;22(10):1290-306.

14. Benowitz NL. Nicotine addiction. N Engl J Med. 2010;362(24):2295-303.

15. Byrne M, Walsh J, Murphy AW. Secondary prevention of coronary heart disease: patient beliefs and health-related behaviour. J Psychosom Res. 2005;58(5):403-15.

16. Chiriboga DE, Ockene JK, Ockene IS. Barriers to preventive interventions for coronary heart disease. Cardiol Clin. 2003;21(3):459-70.

17. Benowitz NL, Prochaska JJ. Smoking cessation after acute myocardial infarction. J Am Coll Cardiol. 2013;61(5):533-5.

18. Munkhaugen J, Sverre E, Peersen K, Gjertsen E, Gullestad L, Moum T, Otterstad JE, Perk J, Husebye E, Dammen T. The role of medical and psychosocial factors for unfavourable coronary risk factor control. Scand Cardiovasc J. 2016;50(1):1-8.
19. Charlson ME, Pompei P, K L. A new method of classifying prognostic comorbidity in longitudinal studies: Development and validation. J Chronic Dis. 1987:40:373-83.

20. Bjelland I, Dahl AA, Haug T, Neckelmann D. The validity of the Hospital Anxiety and Depression Scale. An updated literature review. J Psychosom Res. 2002;52(2):69-77.

21. Denollet J. DS14: standard assessment of negative affectivity, social inhibition, and Type D personality. Psychosom Med. 2005;67(1):89-97.

22. Pallesen S, Nordhus IH, Carlstedt B, Thayer JF, Johnsen TB. A Norwegian adaptation of the Penn State Worry Questionnaire: factor structure, reliability, validity and norms. Scand J Psychol. 2006;47(4):281-91.

23. Pallesen S, Bjorvatn B, Nordhus $H$, Sivertsen B, Hjornevik M, Morin CM. A new scale for measuring insomnia: the Bergen Insomnia Scale. Percept Mot Skills. 2008;107(3):691-706.

24. Broadbent E, Petrie KJ, Main J, Weinman J. The brief illness perception questionnaire. J Psychosom Res. 2006;60(6):631-7.

25. Broadbent E, Petrie KJ, Ellis CJ, Anderson J, Gamble G, Anderson D, Benjamin W. Patients with acute myocardial infarction have an inaccurate understanding of their risk of a future cardiac event. Intern Med J. 2006; 36(10):643-7.

26. Gerber $Y$, Koren-Morag N, Myers $V$, Benyamini $Y$, Goldbourt U, Drory $Y$. Long-term predictors of smoking cessation in a cohort of myocardial infarction survivors: a longitudinal study. Eur J Cardiovasc Prev Rehabil. 2011;18(3):533-41.

27. Dullaghan L, Lusk L, McGeough M, Donnelly P, Herity N, Fitzsimons D. 'I am still a bit unsure how much of a heart attack it really was!' Patients presenting with non ST elevation myocardial infarction lack understanding about their illness and have less motivation for secondary prevention. Eur J Cardiovasc Nurs. 2014;13(3):270-6.

28. Prugger C, Wellmann J, Heidrich J, De Bacquer D, De Backer G, Perier MC, Empana JP, Reiner Z, Fras Z, Jennings $C$, et al. Readiness for smoking cessation in coronary heart disease patients across Europe: Results from the EUROASPIRE III survey. Eur J Prev Cardiol. 2015;22(9):1212-9.

29. Boggon R, Timmis A, Hemingway H, Raju S, Malvestiti FM, Van Staa TP. Smoking cessation interventions following acute coronary syndrome: a missed opportunity? Eur J Prev Cardiol. 2014;21(6):767-73.

30. Perk J, Hambraeus K, Burell G, Carlsson R, Johansson P, Lisspers J. Study of Patient Information after percutaneous Coronary Intervention (SPICl): should prevention programmes become more effective? Eurolntervention. 2015;10(11):e1-7.

31. Mathew AR, Hogarth L, Leventhal AM, Cook JW, Hitsman B. Cigarette smoking and depression comorbidity: systematic review and proposed theoretical model. Addiction. 2017;112(3):401-12.

32. Doyle F, Rohde D, Rutkowska A, Morgan K, Cousins G, McGee H. Systematic review and meta-analysis of the impact of depression on subsequent smoking cessation in patients with coronary heart disease: 1990 to 2013. Psychosom Med. 2014;76(1):44-57.

33. Murphy BM, Grande MR, Navaratnam HS, Higgins RO, Elliott PC, Turner A, Rogerson MC, Worcester MU, Goble AJ. Are poor health behaviours in anxious and depressed cardiac patients explained by sociodemographic factors? Eur J Prev Cardiol. 2013;20(6):995-1003.

34. Svansdottir E, Karlsson HD, Gudnason T, Olason DT, Thorgilsson H, Sigtryggsdottir U, Sijbrands EJ, Pedersen SS, Denollet J. Validity of Type D personality in Iceland: association with disease severity and risk markers in cardiac patients. J Behav Med. 2012;35(2):155-66.

35. Mommersteeg PM, Kupper N, Denollet J. Type D personality is associated with increased metabolic syndrome prevalence and an unhealthy lifestyle in a cross-sectional Dutch community sample. BMC Public Health. 2010;10:714.

36. Murphy BM, Elliott PC, Higgins RO, Le Grande MR, Worcester MU, Goble AJ, Tatoulis J. Anxiety and depression after coronary artery bypass graft surgery: most get better, some get worse. Eur J Cardiovasc Prev Rehabil. 2008;15(4):434-40.

37. Ceccarini M, Manzoni GM, Castelnuovo G. Assessing depression in cardiac patients: what measures should be considered? Depress Res Treat. 2014; 2014:148256. doi:10.1155/2014/148256.

38. West RR, Jones DA, Henderson AH. Rehabilitation after myocardial infarction trial (RAMIT): multi-centre randomised controlled trial of comprehensive cardiac rehabilitation in patients following acute myocardial infarction. Heart. 2012;98(8):637-44.

39. Giannuzzi P, Temporelli PL, Marchioli R, Maggioni AP, Balestroni G, Ceci V, Chieffo C, Gattone M, Griffo R, Schweiger C, et al. Global secondary prevention strategies to limit event recurrence after myocardial infarction: 
results of the GOSPEL study, a multicenter, randomized controlled trial from the Italian Cardiac Rehabilitation Network. Arch Intern Med. 2008; 168(20):2194-204.

40. Anderson L, Thompson DR, Oldridge N, Zwisler AD, Rees K, Martin N, Taylor RS. Exercise-based cardiac rehabilitation for coronary heart disease. Cochrane Database Syst Rev. 2016;1:CD001800.

41. Taylor RS, Brown A, Ebrahim S, Jolliffe J, Noorani H, Rees K, Skidmore B, Stone JA, Thompson DR, Oldridge N. Exercise-based rehabilitation for patients with coronary heart disease: systematic review and meta-analysis of randomized controlled trials. Am J Med. 2004;116(10):682-92.

42. Snaterse M, Scholte Op Reimer WJ, Dobber J, Minneboo M, Ter Riet G, Jorstad HT, Boekholdt SM, Peters RJ. Smoking cessation after an acute coronary syndrome: immediate quitters are successful quitters. Neth Heart J. 2015;23(12):600-7.

43. Lindson-Hawley N, Banting M, West R, Michie S, Shinkins B, Aveyard P. Gradual Versus Abrupt Smoking Cessation: A Randomized, Controlled Noninferiority Trial. Ann Intern Med. 2016;164(9):585-92.

44. Peersen K, Munkhaugen J, Gullestad L, Dammen T, Moum T, Otterstad JE. Reproducibility of an extensive self-report questionnaire used in secondary coronary prevention. Scand J Public Health. 2017;45:269-76.

Submit your next manuscript to BioMed Central and we will help you at every step:

- We accept pre-submission inquiries

- Our selector tool helps you to find the most relevant journal

- We provide round the clock customer support

- Convenient online submission

- Thorough peer review

- Inclusion in PubMed and all major indexing services

- Maximum visibility for your research

Submit your manuscript at www.biomedcentral.com/submit
Biomed Central 